\title{
Early Failure Study of Gearbox Input Shaft Bearing on Damage Rate
}

\author{
Liu Zongqi ${ }^{1,2, a}$, Li Zhiyuan ${ }^{1, b}$, Wang Yongguo ${ }^{2, c}$, Xia Guang $^{1, d}$ \\ ${ }^{1}$ Hefei University of Technology, Hefei, China \\ ${ }^{2}$ Anhui Forklift Truck Group Company key laboratory of Industrial vehicles, Hefei, China \\ ahgdlzq@163.com, bhfutdmc@sohu.com, '53262358@qq.com, dxiaguang008@163.com
}

Keywords: bearing; early failure; damage rate; Romax

\begin{abstract}
In the non-road vehicle transmission systems, it always has early damage in the input shaft bearing. Gearbox simulation model is established by Romax software. Based on the different load spectrum of all shaft bearings and Adjusted bearing damage rate prediction method (instead of ISO 281), rolling bearings are simulated and compared with the actual useful state of those bearings, the results shows that early fretting wear and failure appear on the inner raceway of both input shaft bearings that are connected to engine flywheel due to the vibration of flywheel, input shaft bend, etc. After further study on this failure, the fretting wear mechanism model of input shaft bearing is proposed so that it provides a theoretical reference for the assessment and design of bearings on damage rate of Adjusted method.
\end{abstract}

\section{Introduction}

The gearbox is a very important component in the non-road transport vehicles due to the particularity of the workplace. The frequent manipulation of the transmission is higher than a car many times, working conditions but also has these characteristics: larger load, frequent shifting and conversion of direction. Bearings are important moving parts, the differences of its performance make a great impact on the gearbox, as the input shaft is connected to engine flywheel, bearings at both ends of the shaft are influenced largely by engine, these phenomena are existed such as beating, skid, skew and intense friction between the rolling element and raceway, which makes a greater change in the stress amplitude of the local stress field, then leads to early input shaft fretting wear, fatigue failure, noise, vibration and so on. Therefore, it is necessary for reasonable assessment of the fatigue life and damage conditions of the input shaft bearing.

\section{Virtual Prototype of a Gearbox}

This gearbox is used for 5-10 ton vehicle which is two forward gears and two back gears. A simulation model of a gearbox is built by Romax software and dynamic simulation on different operating conditions of load has been finished. The gearbox principle diagram is shown in Figure 1.

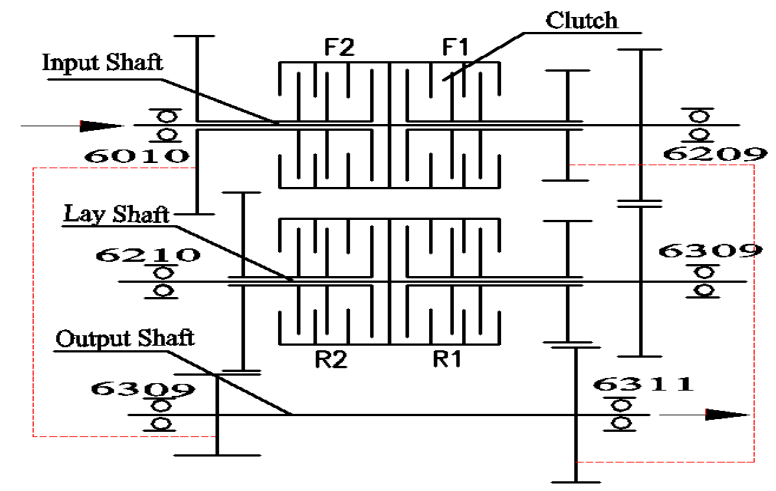

Fig.1 Gearbox principle model

\section{Development of Bearing Fatigue Life Prediction Method}

Bearing Fatigue Life Prediction Theory 
ISO 281 (1990) bearing fatigue life ${ }^{[2]} L_{10, I s o}$ is mainly based on the Lundberg-Palmgren theory ${ }^{[3-5]}$, it only considers the axial and radial loads. Romax Adjusted method bases on the ISO281 life, it considers the real conditions, $L_{10, A d j u s t e d}$ is equal to $L_{10, I S O}$ times $f_{L Z}$, where $f_{L Z}$ is correction coefficient, Adjusted method considers such factors as: the beating of inner and outer raceway, dislocation, bearing preload, contour of the roller, deflection, axial and radial error and so on ${ }^{[1]}$.

\section{Cumulative Bearing Fatigue Life}

Assume that each component has a limited useful fatigue life; each stress cycle (load spectrum) should spend a small part of the life according to the Miner's Rule ${ }^{[6]}$. Failure will occur when the sum of cumulative damage from each load equals to 1:00.

Bearing fatigue life is represented respectively by the ISO 281 life, the ISO 281 damage rate, the Adjusted life, the Adjusted damage rate. The damage rate is an important factor to assess if the bearing load spectrum can meet fatigue life.

\section{Simulation Results Analysis and Failure Mechanism Research}

\section{Gearbox Simulation of the Normal Design}

All shafts are supported by six bearings: two bearings (left 6010 / right 6209) on input shaft, two bearings (left 6010 / right 6209) on lay shaft, two bearings (left 6309 / right 6311) on output shaft. The gearbox has four kinds of conditions (two forward gears, two backward gears) which are corresponding to the different load spectrum(refer with: Table 1), with Romax software simulation, fatigue life and damage rate of six bearings are shown in Figure 2 and Figure 3.

Table 1 Load spectrum on gears

\begin{tabular}{|c|c|c|c|c|}
\hline Gears & F1 & F2 & R1 & R2 \\
\hline Input rotation speed(rpm) & 1652 & 1320 & 1656 & 1280 \\
\hline Input torque (Nm) & 338 & 392 & 336 & 378 \\
\hline Time ratio (\%) & 38 & 14 & 38 & 10 \\
\hline
\end{tabular}

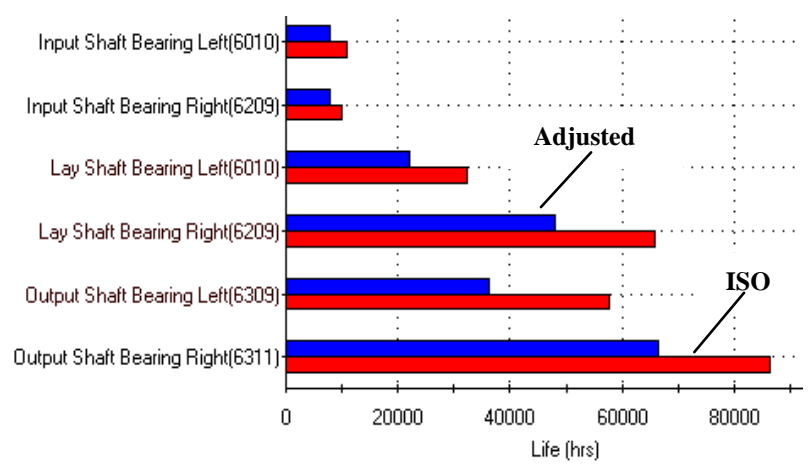

Fig.2 Fatigue life of bears

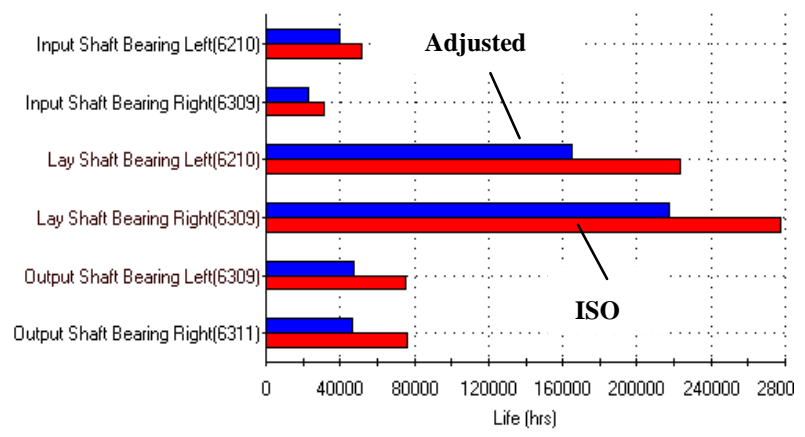

Fig.4 Fatigue life of bears after optimization

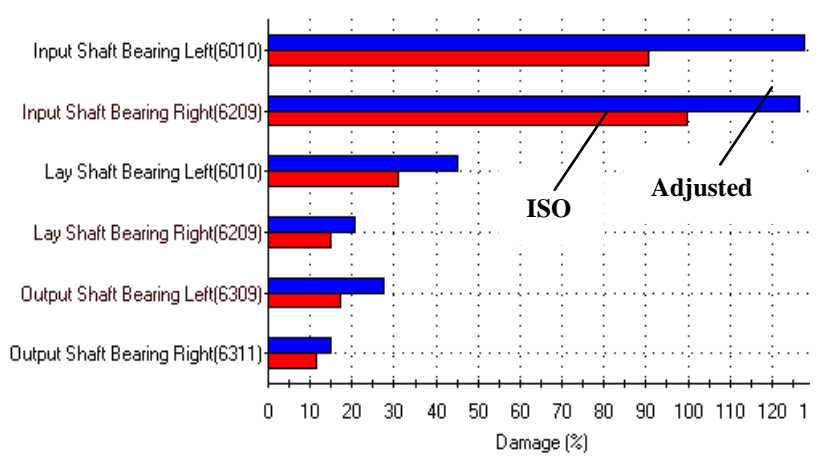

Fig.3 Damage rate of bears

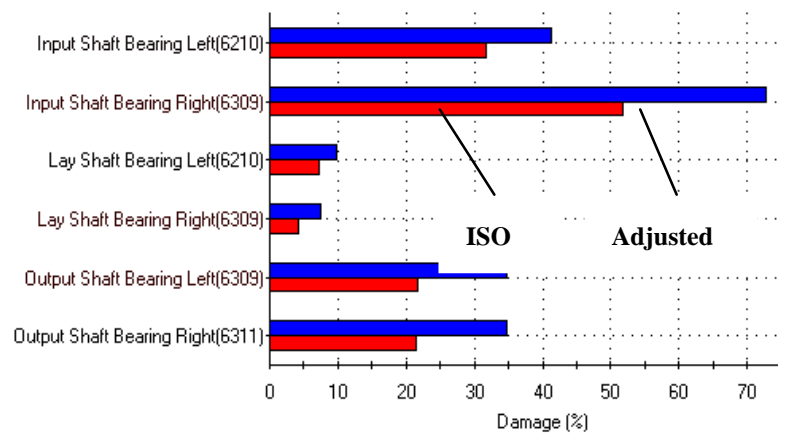

Fig.5 Damage rate of bears after optimization

\section{Gearbox Simulation of the Optimized Design}

As shown in Fig. 2 and Fig. 3, two input shaft bearings(6010/6209)meet the normal design requirement when the damage rates are less than 1 with standard ISO 281, but according to Adjusted method,. the damage rate in simulation results is greater than 1 that is consistent with actual useful phenomenon of early damage and fatigue failure, therefore, the two higher damage rate bearings are 
optimized,. Bearings 6210 and 6309 both replace the bearings 6010 and 6209 respectively, and simulated under the same load spectrum again, the results are shown in Fig. 4 and Fig. 5.

According to the above simulation results (refer with: Fig. 2, Fig. 3, Fig. 4, Fig. 5), two bearings (left 6010 / right 6209) and their optimized bearings (left 6210 / right 6309) are analyzed, the corresponding fatigue life and damage rate on ISO 281 and Adjusted methods are shown in Table 2.

Table 2 Fatigue life and damage rate of Input Shaft bears (normal and optimized design)

\begin{tabular}{|l|c|c|c|c|c|c|c|c|}
\hline Bearings & \multicolumn{2}{|c|}{6010} & \multicolumn{2}{c|}{6209} & \multicolumn{2}{c|}{6210} & \multicolumn{2}{c|}{6309} \\
\hline Item & ISO & Adjusted & ISO & Adjusted & ISO & Adjusted & ISO & Adjusted \\
\hline Fatigue life (h) & 11050 & 8213 & 9972 & 8107 & 52021 & 40385 & 32126 & 21829 \\
\hline Damage rate (\%) & 91.3 & 123.2 & 96.9 & 120.5 & 33.8 & 42.5 & 52.9 & 73.5 \\
\hline
\end{tabular}

\section{Analysis of Simulation Results and Research of Failure Mechanism}

\section{1) Analysis of simulation results}

From Tables 2, in the normal bearing design, ISO 281 damage rates of the bearings 6010 and 6209 are $91.3 \%$ and $96.9 \%$, both are less than 1, their fatigue lives are 11050 hours and 9972 hours, but in the actual operation condition of two shifts works enterprises (such as paper, furniture and etc.), in a period of less than 2 years, early fretting wear and tilt peeling area are found on the working surface of the bearing inner raceway and rolling element (refer with: Fig. 7, Fig. 8), which leads to vibration and noise, this early failure in actual use is consistent with the simulation results on the Adjusted method which show the damage rates actually are $123.2 \%$ and $120.5 \%$ that are greater than 1, and their fatigue lives of 8213 hours and 8107 hours are decreased by $25.67 \%$ and $18.7 \%$ than the ISO 281 standard value, and that can not meet the actual useful requirements. It indicates that some unfavorable factors lead to the early failure. To this end we optimized the design of the normal input shaft bearing, and optimal damage rates are greatly reduced to $42.5 \%$ and $73.5 \%$, the optimal fatigue life has been greatly increased and able to meet the expected life requirement.

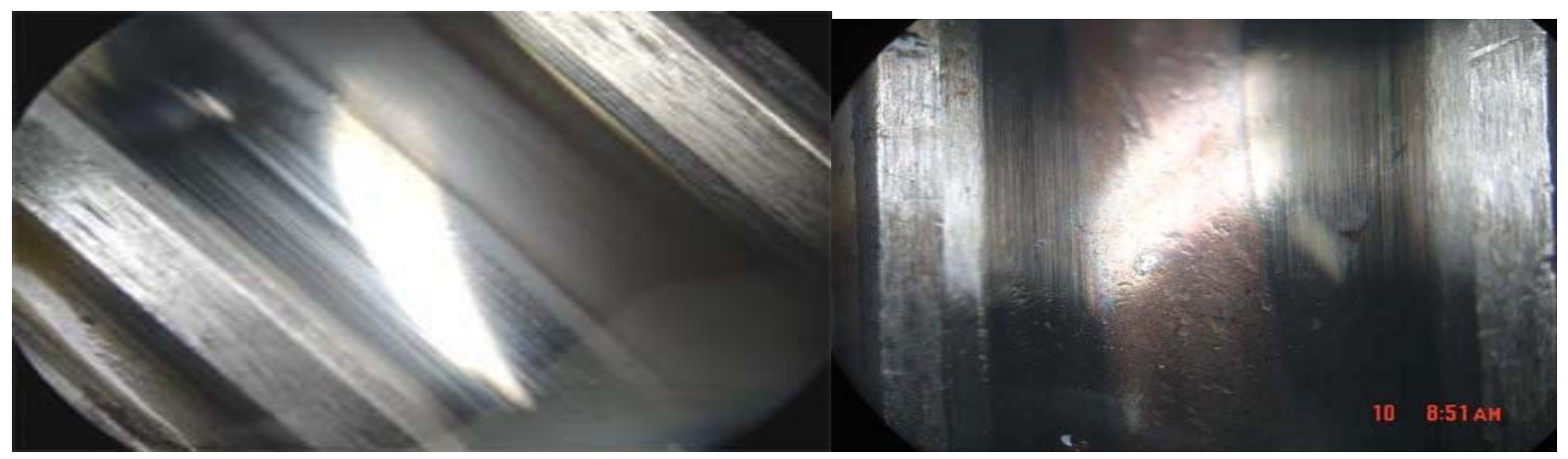

Fig.7 Early fretting wear on bearing inner ring groove surface

Fig.8 Pitting corrosion on bearing inner ring groove surface

\section{2) Research of failure Mechanism:}

As the early failure's input shaft is in special location, which is directly connected to the engine flywheel, the vibration generated by the piston reciprocating motion have great and more complex influence on bearings fretting failure. The periodicity of piston acceleration characteristics which changes with the frequency makes the crankshaft multiple frequency vibration. According to the simplified sphere-plane contact model theory and their relative movement direction, the rolling motion of two bearing not only have tangential fretting and radial fretting, but also rotational fretting, the frequency of three kinds of fretting is many times than the one of the engine rotation speed, so that fretting damage is much more serious. Considering the complex motion of the rolling element of the input shaft bearing, the model of a generalized fretting wear mechanism is proposed(refer with: Fig. 9), the model of mechanism provide a theoretical reference for the analysis of complex load frequency and amplitude on the Romax Adjusted method. 


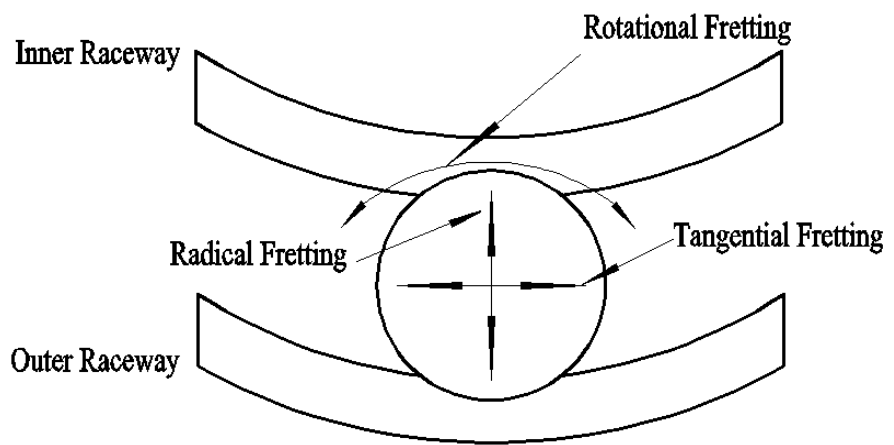

Fig.9 Generalized composite fretting wear mechanism model

\section{Conclusion}

1) The load of gearbox input shaft bearing is complex, the early fretting wear and shortened life appeared on two input shaft bearings, Romax simulation analysis shows that the ISO 281 method is less damage rates than Adjusted one, there is a certain degree of error to the actual condition in the design of the gearbox input shaft bearings on the standard method.

2) The characteristics of engine piston acceleration and frequency are a large impact on the input shaft bearing fretting wear, a generalized fretting wear mechanism model of the input shaft bearing is established, and the model provides theoretical basis for the Romax Adjusted analysis method.

3) To optimize the design of two higher damage rates bearings on ISO 281 method, Adjusted method is able to consistent with the actual working condition of bearings, its data of damage rate and fatigue life can be taken as an important basis for transmission design and assessment.

\section{References}

[1] Romax Designer R12.1-Bearing Application Notes [R]. Romax Technology Ltd, UK, 2004:6-18.

[2] ASME. Life Adjustment factors for Ball and Roller Bearing [J].ASME, 1971:32-34

[3] Lundberg G,Palmgren A. Dynamic Capacity of Rolling Bearings [J].Acta Polytech.Mech.Eng. Ser.1, R.S.A.E, No.3.7, 1947:12-36.

[4] Cha Quan,Chen Junjing, Rolling bearing new calculation method for life prediction [J]. Bearing, 2001, (4) :1-6.

[5] Wang Xianfeng, Chen Ke, Rolling bearing life theory in the development [J].bearing, 2002, (9):36-40.

[6] Miner, M. A,"Cumulative Damage in Fatigue," Journal of Applied Mechanics, Trans. ASME Vol. 67, 1945:159-16

[7] Berthier Y,Colombie Ch et al. , Fretting wear mechanism and their effect on fretting fatigue. Tribology, 1998,110: 517-524 